\title{
Effects of Pasteurization on Adiponectin and Insulin Concentrations in Donor Human Milk
}

\author{
SYLVIA H. LEY, ANTHONY J. HANLEY, DEBBIE STONE, AND DEBORAH L. O'CONNOR \\ Department of Nutritional Sciences [S.H.L., A.J.H., D.L.O.], University of Toronto, Toronto M5S 3E2, Canada; Department of Clinical \\ Dietetics [D.S., D.L.O.], Physiology and Experimental Medicine Program [D.L.O.], Hospital for Sick Children, Toronto M5G 1X8, Canada
}

\begin{abstract}
Although pasteurization is recommended before distributing donor human milk in North America, limited data are available on its impact on metabolic hormones in milk. We aimed to investigate the effects of pasteurization on adiponectin and insulin concentrations in donor human milk. The study investigates concentrations of components in donor human milk before and after Holder pasteurization. After the guidelines of the Human Milk Bank Association of North America, human milk samples were pooled to produce 17 distinct batches (4 individuals per batch) and pasteurized at $62.5^{\circ} \mathrm{C}$ for $30 \mathrm{~min}$. Adiponectin, insulin, energy, fat, total protein, and glucose concentrations were measured pre- and postpasteurization. Pasteurization reduced milk adiponectin and insulin by 32.8 and $46.1 \%$, respectively (both $p<0.0001$ ). Adiponectin and insulin were significantly correlated with energy and fat milk composition $(r=$ 0.36-0.47; all $p<0.05$ ). Pasteurization effects on milk hormone concentrations remained significant after adjusting for fat and energy (beta \pm SEE: $-4.11 \pm 1.27, p=0.003$ for adiponectin; $-70.0 \pm$ $15.0, p<0.0001$ for insulin). Holder pasteurization reduced adiponectin and insulin concentrations in donor human milk. In view of emerging knowledge on the importance of milk components, continued work to find the optimal pasteurization process that mitigates risks but promotes retention of bioactive components is needed. (Pediatr Res 70: 278-281, 2011)
\end{abstract}

$\mathrm{T}$ he epidemic in childhood obesity is a major public health challenge, which is reflected in the rapidly increasing rates of youth onset type 2 diabetes $(1,2)$. Epidemiological evidence has shown a protective effect of breastfeeding on obesity $(3,4)$ and type 2 diabetes later in life $(5)$. Human milk contains not only macro- and micronutrients but also an array of bioactive substances including insulin $(6,7)$. More recently, adiponectin, an insulin-sensitizing hormone in serum (8), has been detected in human milk $(9-11)$. Therefore, these metabolic hormones may explain the observed association of breastfeeding with reduced risk for metabolic disease in offspring later in life (12).

With improved knowledge about the benefits of breastfeeding, there has been increasing demand for donor milk when mother's own milk is not available (13). To protect recipients

Received December 1, 2010; accepted February 28, 2011.

Correspondence: Deborah L. O'Connor, Ph.D., Department of Nutritional Sciences, University of Toronto, The Hospital for Sick Children, Room 8511C, 555 University Avenue, Toronto, ON M5G 1X8, Canada; e-mail: deborah_l.oconnor@sickkids.ca

Supported by grants from the Canadian Diabetes Association (CDA), Canadian Foundation for Dietetic Research, and Canadian Institutes of Health Research (CIHR); a CIHR Frederick Banting and Charles Best Canada Graduate Scholarship [S.H.L.]; CIHR Canada Research Chair in the Epidemiology of Type 2 Diabetes and Ontario Ministry of Research and Innovation Early Researcher Award [A.J.H.]. against disease transmission, donor milk undergoes safety screening and handling processes (14-17). These processes, however, vary among countries: donor milk is pasteurized at $62.5^{\circ} \mathrm{C}$ for $30 \mathrm{~min}$ (Holder method) before distribution in North America and the United Kingdom (14,15), whereas donor milk is pasteurized at a lower temperature or unpasteurized in other countries $(16,17)$. Although various nutrient components remain intact after pasteurization, the pasteurization process is known to effect biological activity of a number of milk components (18). Although the concentrations of adiponectin and insulin have been reported in human milk previously $(9,10)$, the effect of pasteurization on these metabolic hormones has not been investigated. With recent evidence from a randomized controlled study demonstrating that dietary intervention in infancy has long-term effects on beta cell autoimmunity (19), it is important to understand the impact of pasteurization on milk metabolic hormones, which may have a critical impact on infant metabolic trajectories $(20,21)$. We therefore aimed to investigate the effects of Holder pasteurization on adiponectin and insulin concentrations in donor human milk.

\section{METHODS}

The study was approved by the Hospital for Sick Children Ethics Review Committee, and informed consent was obtained from all milk donors. The inclusion criteria of donor milk samples were that milk needed to be expressed at $>1$ mo postpartum and $<1 \mathrm{yr}$. This was to avoid inclusion of colostrum and transitional milk samples and milk from an involuting mammary gland. Donor milk from 34 women, frozen immediately and stored at $-20^{\circ} \mathrm{C}$ for $<6 \mathrm{mo}$, were used for the current analysis. After thawing individual milk samples in a water bath at $37.5^{\circ} \mathrm{C}$, milk was pooled and processed following the guidelines of the Human Milk Bank Association of North America (14). Distinct batches of 17 pooled samples were produced with each batch comprising milk from four women. Samples were divided into 2 sets of 17 batches to assess pre- and postpasteurization effects. Samples for postpasteurization analysis were processed in a Breast Milk Pasteurizer (T30/USA; Sterifeed, Medicare Colgate Ltd, United Kingdom), which involved submerging bottles into a preheated water bath $\left(63.2^{\circ} \mathrm{C}\right)$ followed by a cool water bath $\left(<9^{\circ} \mathrm{C}\right)$. A temperature probe was positioned in a centrally placed nonsample bottle to ensure milk samples were maintained at $62.5^{\circ} \mathrm{C}$ for $30 \mathrm{~min}$. Pre- and postpasteurization samples were aliquoted and stored at $-80^{\circ} \mathrm{C}$ until biochemical analysis.

Biochemical analysis and validation of adiponectin assay. Adiponectin concentration was measured using a RIA (Millipore, Linco Research, MO). This assay has an interassay coefficient of variation of $9.3 \%$ at $7.5 \mu \mathrm{g} / \mathrm{L}$. To validate assay methods for adiponectin, whole milk samples were spiked with $5,10,20$, or $40 \mathrm{ng} / \mathrm{mL}$ human adiponectin standards (Millipore, Linco Research) to determine the recovery of the added volume. To account for sample dilution effects due to the added spiking volume, an equivalent volume 
of physiological saline containing $0 \mathrm{ng} / \mathrm{mL}$ adiponectin was added to control nonspiked samples. Therefore, each adiponectin spiked sample had its own control designated as baseline. To assess whether lipids interfered with the adiponectin assay, 12 nonspiked study samples ( 6 pre- and 6 postpasteurization pooled batches) were assayed using both whole and skim milk samples. Skim milk samples were centrifuged (3000 revolutions per minute for 15 $\mathrm{min}$ ), and the fat layer was removed.

Insulin concentration in skim milk was measured using the electrochemiluminescence immunoassay (Modular Analytics E170; Roche, NJ). This assay shows $0.05 \%$ cross-reactivity to intact human proinsulin and the primary circulating split form (des 31,32). Total energy was determined by bomb calorimetry using the 1241 Automatic Adiabatic Calorimeter (Parr Instrument Company, IL) according to the method described by Garza et al. (22). Total fat was determined using the Creamatocrit methodology described by Lucas et al. (23). Total protein was measured using the Bicinchoninic Acid protein assay kit (Sigma Chemical Co., MO) (24). Glucose concentration in skim milk was determined using the hexokinase enzymatic method (Modular Analytics E170; Roche). All study sample assays including nutrient compositions were performed on two sets (pre- and postpasteurization) of 17 pooled batches.

Statistical analysis. Data analyses were performed using SAS software, version 9.2 (SAS Institute, NC) and with the consideration of two-sided $p<$ 0.05 as statistically significant for all analyses. Distributions of continuous variables were assessed for normality and were determined to follow a normal distribution.

Descriptive statistics for continuous variables were summarized as mean \pm SD. Concentrations of milk components pre- and postpasteurization were compared using paired $t$ tests. To assess correlations of adiponectin and insulin with potential covariate milk components, Spearman rank correlation analysis was performed.

To evaluate effects of pasteurization as a main exposure on the outcomes of adiponectin and insulin with adjustment for potential covariates, we used mixed model analysis that is similar to analysis of covariance except the analysis accounts for correlation within the batches related to the repeated measure design. Three models were tested for each outcome variable: 1) an unadjusted model; 2) a model adjusted for total fat; and 3) a model adjusted for total fat and energy.

\section{RESULTS}

Average recovery rates of spiked adiponectin from whole and skim milk samples were $105.5 \pm 18.2 \%$ (mean \pm SD) and $118.4 \pm 36.0 \%$, respectively. Nonspiked adiponectin concentrations of whole and skim milk samples were highly correlated $\left(r_{\text {spearman }}=0.90\right.$ and $r_{\text {pearson }}=0.97$, both $p<0.0001$; Fig. 1), and mean adiponectin concentrations of whole $(12.3 \pm 6.1 \mathrm{ng} / \mathrm{mL})$ and skim $(12.1 \pm 5.4)$ milk were not significantly different. Based on these similar findings, adiponectin concentrations in study milk samples were measured using whole milk.

Pasteurization reduced the concentration of milk adiponectin by $32.8 \%$ (pre- and postmean \pm SD: $13.9 \pm 4.8 v s 9.3 \pm$

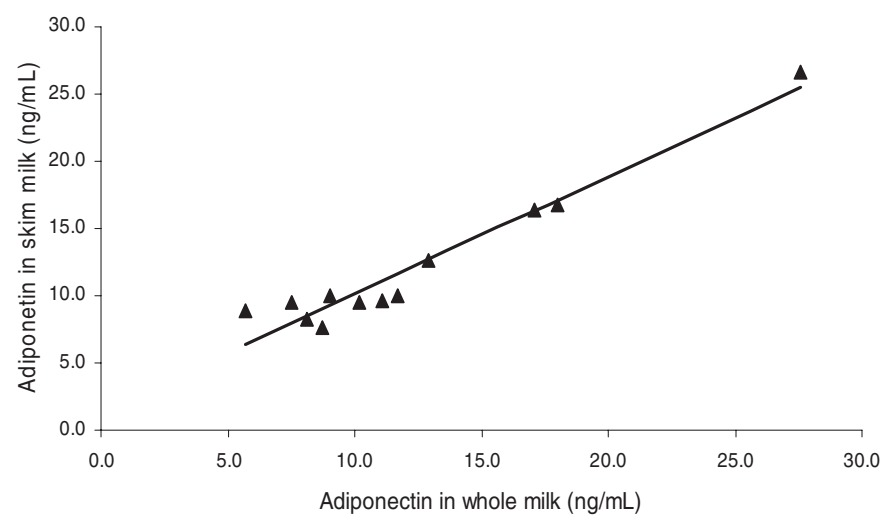

Figure 1. Comparison of adiponectin concentrations in skim and whole milk. The solid line represents the linear regression line $\left(r_{\text {spearman }}=0.90\right.$ and $r_{\text {pearson }}=0.97$.
$3.0 \mathrm{ng} / \mathrm{mL} ; p<0.0001)$ and insulin by $46.1 \%(162.8 \pm 64.2$ vs $87.8 \pm 26.3 \mathrm{pmol} / \mathrm{L} ; p<0.0001$ ), whereas changes in energy, total fat, total protein, and glucose concentrations were modest, ranging $0-8.9 \%$ (Table 1 ).

As assessed by Spearman correlation, adiponectin was significantly correlated with energy and fat composition in milk $(r=0.47$ and 0.41 , respectively; both $p<0.05$ ) but not with protein and glucose $(r=0.04$ and -0.08 , respectively). Similarly, insulin was significantly correlated with energy and fat composition in milk ( $r=0.41$ and 0.36 , respectively; both $p<0.05)$ but not with protein and glucose $(r=-0.21$ and 0.09 , respectively).

The effects of pasteurization as a main exposure on the outcome of adiponectin or insulin were assessed with adjustment for significantly correlated potential covariates. Pasteurization effects on milk hormone concentrations remained significant after adjusting for fat and energy and accounting for correlations within the same batches (beta \pm SEE: $-4.11 \pm$ $1.27, p=0.003$ for adiponectin; $-70.0 \pm 15.0, p<0.0001$ for insulin; Table 2).

\section{DISCUSSION}

We report that Holder pasteurization recommended in North America reduced adiponectin and insulin concentrations in donor human milk. Pasteurization effects on milk hormone concentrations remained significant with adjustment for potential covariates including milk fat.

To prevent transmission of bacteria and pathogens including HIV and human T-lymphotropic virus, donor milk banks have implemented safety screening and handling processes (14-17). Although donor milk is Holder pasteurized before distribution in North America and the United Kingdom $(14,15)$, some countries have implemented more detailed screening processes followed by a lower temperature pasteurization or no pasteurization $(16,17)$. Although a number of nutrients are unaffected by pasteurization (18), the pasteurization process deactivates or reduces the activity of several bioactive components in human milk including immunological proteins $(18,25)$. Our results, which demonstrate that pasteurization reduced adiponectin and insulin concentrations in donor milk, raise concerns considering these hormones may have an important role in the metabolic development of infants $(20,21)$. Although the molecular mechanism by which these metabolic hormones in milk may provide protection against developing metabolic disease later in life is not completely understood, potential mechanisms and physiological roles of these hormones influencing infant metabolic trajectories have been reviewed $(12,20,21)$. Evidence indicates that oral administration of insulin stimulates gut maturation (21) and that adiponectin receptors are present in the fetal small intestine (20). These milk metabolic hormones, therefore, may have a direct role in the optimal metabolic development of infants and subsequently in reducing susceptibility to future metabolic disease. This may be especially important for the primary recipients of donor milk, preterm very LBW infants who are at increased risk for insulin resistance and type 2 diabetes later in life (26-28). 
Table 1. Concentrations of human milk components pre- and postpasteurization

\begin{tabular}{|c|c|c|c|c|c|}
\hline \multirow[b]{2}{*}{ Component } & \multicolumn{2}{|c|}{ Mean \pm SD } & \multirow{2}{*}{$\begin{array}{c}\text { Mean of } \\
\text { differences } \pm \text { SEM }\end{array}$} & \multirow[b]{2}{*}{$p^{*}$} & \multirow{2}{*}{$\begin{array}{r}\text { Observed } \\
\text { change }(\%\end{array}$} \\
\hline & Pre & Post & & & \\
\hline Adiponectin (ng/mL) & $13.91 \pm 4.84$ & $9.34 \pm 2.96$ & $-4.57 \pm 0.61$ & $<0.0001$ & -32.8 \\
\hline Insulin $(\mathrm{pmol} / \mathrm{L})$ & $162.8 \pm 64.2$ & $87.8 \pm 26.3$ & $-74.9 \pm 11.1$ & $<0.0001$ & -46.1 \\
\hline Energy $(\mathrm{kcal} / \mathrm{dL})$ & $71.5 \pm 9.9$ & $69.4 \pm 8.8$ & $-2.2 \pm 1.5$ & 0.17 & -2.9 \\
\hline Fat $(\mathrm{g} / \mathrm{L})$ & $4.29 \pm 0.95$ & $3.91 \pm 0.81$ & $-0.38 \pm 0.15$ & 0.02 & -8.9 \\
\hline Glucose $(\mathrm{mmol} / \mathrm{L})$ & $0.97 \pm 0.25$ & $1.11 \pm 0.22$ & $0.13 \pm 0.03$ & 0.0007 & 1.4 \\
\hline Protein (g/L) & $14.8 \pm 1.5$ & $14.8 \pm 1.1$ & $-0.02 \pm 0.37$ & 0.97 & $<0.1$ \\
\hline
\end{tabular}

* Paired $t$ test.

Table 2. Milk adiponectin and insulin concentrations pre-and postpasteurization

\begin{tabular}{|c|c|c|c|c|c|c|c|c|}
\hline \multirow[b]{2}{*}{ Models } & \multicolumn{4}{|c|}{ Adiponectin $(95 \% \mathrm{CI}), \mathrm{ng} / \mathrm{mL}$} & \multicolumn{4}{|c|}{ Insulin $(95 \% \mathrm{CI}), \mathrm{pmol} / \mathrm{L}$} \\
\hline & Beta \pm SEM & Pre & Post & $p$ & Beta \pm SEE & Pre & Post & $p$ \\
\hline 1 & $-4.57 \pm 1.36$ & $14.8(11.9-17.6)$ & $10.2(8.0-12.4)$ & 0.002 & $-74.9 \pm 15.5$ & $186.2(151.4-220.9)$ & $111.2(89.3-133.2)$ & $<0.0001$ \\
\hline 2 & $-4.03 \pm 1.30$ & $15.0(12.2-17.9)$ & $11.0(8.6-13.4)$ & 0.004 & $-69.7 \pm 15.0$ & $187.0(153.8-220.2)$ & $117.4(96.2-138.5)$ & $<0.0001$ \\
\hline 3 & $-4.11 \pm 1.27$ & $14.5(11.8-17.1)$ & $10.4(8.1-12.6)$ & 0.003 & $-70.0 \pm 15.0$ & $184.9(151.2-218.6)$ & $114.9(92.5-137.4)$ & $<0.0001$ \\
\hline
\end{tabular}

Mixed models were used accounting for correlations within the same batches. Models are 1) unadjusted, 2) adjusted for total fat, and 3) adjusted for total fat and energy.

In human serum, high-molecular weight (HMW) adiponectin is known to be the most biologically active form that has stronger associations with diabetes risk than total adiponectin (8). It must be noted that we used the total adiponectin assay that is not specific to the HMW form of adiponectin. Adiponectin in human milk, however, has been reported to be almost entirely composed of the HMW form (20). We also note that the heat treatment at $70^{\circ} \mathrm{C}$ for $10 \mathrm{~min}$ denatures adiponectin from trimeric to monomeric forms (29). Therefore, it is possible that Holder pasteurization might have reconfigured the adiponectin molecule such that it was unrecognizable to the assay. This unrecognizable molecule, however, is likely to be also nonfunctional. If this nonfunctional molecule in pasteurized milk was detected by the assay, pasteurized milk would have even greater reduction in its bioactivity. However, the functional analysis was not performed in the current study, which is another limitation of the study. In addition, we report the pasteurization effects on donor milk components but not other donor milk handling processes including freeze-thaw cycles. Previously, Bronsky et al. (10) reported a strong correlation between adiponectin concentrations before and after two freeze-thaw cycles $(r=$ 0.894, $p<0.0001$ ). Although Holder pasteurization is likely a major attributor that alters adiponectin and insulin concentrations, we cannot conclude that the impact of the overall donor milk processing protocol on milk composition is not greater than the pasteurization effects reported here. We also cannot separate effects of each pasteurization step, including heat treatment and container changes, on concentrations of milk components based on our results. Although the magnitude of changes in pre- and postpasteurization fat and glucose concentrations were small, they were significant. We speculate that the fat content might have been reduced during the donor milk handling process as a result of multiple container transfers. As for glucose concentrations, the pasteurization process might have caused molecular reconfigurations exposing more glucose molecules to be recognized by the assay. These hypotheses, however, were not tested in the current study. The strength of our report is that we investigated the practical impact of Holder pasteurization on donor milk following the standardized processing protocol (14).

In conclusion, Holder pasteurization, currently recommended by the Human Milk Banking Association of North America, reduced adiponectin and insulin concentrations in donor human milk. Because insulin and adiponectin are known to be involved in the pathophysiology of diabetes (8), the impact of the reduction in these milk hormones on susceptibility for developing type 2 diabetes later in life warrants further investigation. Variation in heat treatment options including a reduction in the length of pasteurization has been shown to preserve insulin-like growth factors (30). In addition, reducing pasteurization temperature to $57^{\circ} \mathrm{C}$ improved immunological protein retention while effectively removing $99.9 \%$ of inoculated bacterial species (25). With recent evidence from a randomized controlled study demonstrating long-term benefit of dietary intervention in infancy (19), it is important to understand the effect of pasteurization on milk components that may have a critical impact on infant metabolic trajectories $(20,21)$. In view of emerging knowledge on the importance of milk components on human health outcomes, comprehensive risk and benefit assessments to find the optimal pasteurization process that mitigates risks but promotes retention of bioactive components is needed.

Acknowledgments. We thank the Banting and Best Diabetes Centre Core Laboratory for their assistance in milk validation assays. We thank Sarah Harvey and Nisha Pai for their technical assistance.

\section{REFERENCES}

1. Hannon TS, Rao G, Arslanian SA 2005 Childhood obesity and type 2 diabetes mellitus. Pediatrics 116:473-480

2. Sinha R, Fisch G, Teague B, Tamborlane WV, Banyas B, Allen K, Savoye M, Rieger V, Taksali S, Barbetta G, Sherwin RS, Caprio S 2002 Prevalence of impaired glucose tolerance among children and adolescents with marked obesity. N Engl J Med 346:802-810 
3. Owen CG, Martin RM, Whincup PH, Smith GD, Cook DG 2005 Effect of infan feeding on the risk of obesity across the life course: a quantitative review of published evidence. Pediatrics 115:1367-1377

4. Arenz S, Ruckerl R, Koletzko B, von Kries R 2004 Breast-feeding and childhood obesity - a systematic review. Int J Obes Relat Metab Disord 28:1247-1256

5. Owen CG, Martin RM, Whincup PH, Smith GD, Cook DG 2006 Does breastfeeding influence risk of type 2 diabetes in later life? A quantitative analysis of published evidence. Am J Clin Nutr 84:1043-1054

6. Read LC, Upton FM, Francis GL, Wallace JC, Dahlenberg GW, Ballard FJ 1984 Changes in the growth-promoting activity of human milk during lactation. Pediatr Res 18:133-139

7. Hamosh M 2001 Bioactive factors in human milk. Pediatr Clin North Am 48:69-86

8. Li S, Shin HJ, Ding EL, van Dam RM 2009 Adiponectin levels and risk of type 2 diabetes: a systematic review and meta-analysis. JAMA 302:179-188

9. Martin LJ, Woo JG, Geraghty SR, Altaye M, Davidson BS, Banach W, Dolan LM, Ruiz-Palacios GM, Morrow AL 2006 Adiponectin is present in human milk and is associated with maternal factors. Am J Clin Nutr 83:1106-1111

10. Bronsky J, Karpisek M, Bronska E, Pechova M, Jancikova B, Kotolova H, Stejskal D, Prusa R, Nevoral J 2006 Adiponectin, adipocyte fatty acid binding protein, and epidermal fatty acid binding protein: proteins newly identified in human breast milk. Clin Chem 52:1763-1770

11. Weyermann M, Beermann C, Brenner H, Rothenbacher D 2006 Adiponectin and leptin in maternal serum, cord blood, and breast milk. Clin Chem 52:2095-2102

12. Bartok CJ, Ventura AK 2009 Mechanisms underlying the association between breastfeeding and obesity. Int J Pediatr Obes 4:196-204

13. Tully MR 2000 A year of remarkable growth for donor milk banking in North America. J Hum Lact 16:235-236

14. Human Milk Banking Association of North America 2009 Guidelines For the Establishment and Operation of a Donor Human Milk Bank. 15th ed. Human Milk Banking Association of North America, Fort Worth, pp 1-28

15. National Institute for Health and Clinical Excellence 2010 Donor breast milk banks: the operation of donor milk bank services. National Institute for Health and Clinical Excellence, London. Available at: http://www.nice.org.uk/nicemedia/live/12811/ 47545/47545.pdf. Accessed, November 15, 2010

16. Springer S 1997 Human milk banking in Germany. J Hum Lact 13:65-68

17. Grøvslien AH, Grønn M 2009 Donor milk banking and breastfeeding in Norway. J Hum Lact 25:206-210
18. Tully DB, Jones F, Tully MR 2001 Donor milk: what's in it and what's not. J Hum Lact 17:152-155

19. Knip M, Virtanen SM, Seppä K, Ilonen J, Savilahti E, Vaarala O, Reunanen A, Teramo K, Hämäläinen AM, Paronen J, Dosch HM, Hakulinen T, Akerblom HK; Finnish TRIGR Study Group 2010 Dietary intervention in infancy and later signs of beta-cell autoimmunity. N Engl J Med 363:1900-1908

20. Newburg DS, Woo JG, Morrow AL 2010 Characteristics and potential functions of human milk adiponectin. J Pediatr 156:S41-S46

21. Shehadeh N, Sukhotnik I, Shamir R 2006 Gastrointestinal tract as a target organ for orally administered insulin. J Pediatr Gastroenterol Nutr 43:276-281

22. Garza C, Butte NF, Dewey KG 1985 Determination of the energy content of human milk. In: Jensen RG, Neville MC (eds) Human Lactation: Milk Components and Methodologies. Plenum Press, New York pp 121-125

23. Lucas A, Gibbs JA, Lyster RL, Baum JD 1978 Creamatocrit: simple clinical technique for estimating fat concentration and energy value of human milk. BMJ $1: 1018-1020$

24. Keller RP, Neville MC 1986 Determination of total protein in human milk: comparison of methods. Clin Chem 32:120-123

25. Czank C, Prime DK, Hartmann B, Simmer K, Hartmann PE 2009 Retention of the immunological proteins of pasteurized human milk in relation to pasteurizer design and practice. Pediatr Res 66:374-379

26. Hofman PL, Regan F, Jackson WE, Jefferies C, Knight DB, Robinson EM, Cutfield WS 2004 Premature birth and later insulin resistance. N Engl J Med 351:2179-2186

27. Hovi P, Andersson S, Eriksson JG, Järvenpää A-L, Strang-Karlsson S, Mäkitie O, Kajantie E 2007 Glucose regulation in young adults with very low birth weight. N Engl J Med 356:2053-2063

28. Kaijser M, Edstedt Bonamy A-K, Akre O, Cnattingius S, Granath F, Norman M, Ekbom A 2009 Perinatal risk factors for diabetes in later life. Diabetes 58:523-526

29. Waki H, Yamauchi T, Kamon J, Ito Y, Uchida S, Kita S, Hara K, Hada Y, Vasseur F, Froguel P, Kimura S, Nagai R, Kadowaki T 2003 Impaired multimerization of human adiponectin mutants associated with diabetes. Molecular structure and multimer formation of adiponectin. J Biol Chem 278:40352-40363

30. Goelz R, Hihn E, Hamprecht K, Dietz K, Jahn G, Poets C, Elmlinger M 2009 Effects of different CMV-heat-inactivation-methods on growth factors in human breast milk. Pediatr Res 65:458-461 